\title{
PAMAM and polyester dendrimers as favipiravir nanocarriers: a comparative study using DFT method
}

\author{
Sekineh Bazyari-Delavar • \\ Farideh Badalkhani-Khamseh • \\ Azadeh Ebrahim-Habibi · Nasser L. Hadipour
}

Received: 20 October 2020 / Accepted: 24 May 2021 / Published online: 20 October 2021

(C) Springer Nature B.V. 2021

\begin{abstract}
The electronic sensitivity and reactivity of polyamidoamine (PAMAM) and polyester dendrimers toward favipiravir (T705) were inspected using density functional theory method. The T705 drug is adsorbed on the surface of PAMAM and polyester dendrimers with the binding energy of -27.26 and $-26.80 \mathrm{kcal} \mathrm{mol}^{-1}$, respectively, in the solvent phase. The energy gap of PAMAM and polyester dendrimers reduced by about $32 \%$ and $27 \%$, indicating that the electrical conductance of carriers become $8.16 \times 10^{23}$ and $4.41 \times 10^{22}$ times higher, upon T705 adsorption. The work function $(\Phi)$ value of PAMAM and polyester is changed about 1.53 and $0.71 \mathrm{eV}$, respectively. Thus, PAMAM dendrimer is about 2.5 times stronger $\Phi$-type sensor than polyester dendrimer.
\end{abstract}

\footnotetext{
S. Bazyari-Delavar · F. Badalkhani-Khamseh ( $\bowtie)$.

N. L. Hadipour $(\bowtie)$

Department of Physical Chemistry, Tarbiat Modares

University, Tehran, Iran

e-mail: f.badalkhani@modares.ac.ir

N. L. Hadipour

e-mail: hadipour@modares.ac.ir
}

\section{A. Ebrahim-Habibi}

Biosensor Research Center, Endocrinology and Metabolism Molecular-Cellular Sciences Institute,

Tehran University of Medical Sciences, Tehran, Iran

A. Ebrahim-Habibi

Endocrinology and Metabolism Research Center, Endocrinology and Metabolism Clinical Sciences Institute,

Tehran University of Medical Sciences, Tehran, Iran
The recovery time for T705 desorption from the PAMAM and polyester surface is predicted to be $9.2 \times 10^{3}$ and $4.2 \times 10^{3} \mathrm{~s}$, respectively, at physiological environment.

Keywords PAMAM dendrimer · Polyester dendrimer $\cdot$ Favipiravir (T705) $\cdot$ Density functional theory $(\mathrm{DFT}) \cdot$ Nanocarriers

\section{Introduction}

Dendrimers are core-shell nanostructures with high size uniformity, low polydispersity, and a large number of functional groups at the chain ends, which can be easily tailored based on the guest (drug or ligand) molecule requirements (Tomalia 2004; Dias et al. 2019; Badalkhani-Khamseh et al. 2019). Due to the presence of a hydrophobic interior and a hydrophilic surface layer in their structure, dendrimers enhance the solubility and consequently bioavailability of hydrophobic drugs by encapsulating them within the dendritic structure (Kesharwani et al. 2014; Chauhan et al. 2020; Badalkhani-Khamseh et al. 2017a). Also, they allow the mixing of hydrophilic and hydrophobic compounds in catalytic applications (Yamamoto et al. 2019) and could be of great relevance in co-delivery of hydrophobic/hydrophilic drugs for enhanced synergistic treatment. In recent decades, a number of dendritic scaffolds have been synthesized with nanosize and shape having different functionalities and 
applications including poly(amidoamine) (PAMAM), poly(propylene imine) (PPI), triazine, and polyester dendrimers (Esfand and Tomalia 2001; Parrott et al. 2009; Lim and Simanek 2012; Feliu et al. 2012; Pedziwiatr-Werbicka et al. 2019; Parashar et al. 2019).

Since their synthesis in 1985 (Tomalia et al. (1985)), PAMAM dendrimers have been the most frequently studied dendrimers to solve the problems related to targeted drug delivery (Akhtar et al. 2019; Holmes et al. 2019; Kheiriabad et al. 2020; Badalkhani-Khamseh et al. 2017b). However, PAMAM dendrimers are not biodegradable in vivo, which hinders their translation to clinical trials (Fischer et al. 2003; Hong et al. 2006; Winnicka et al. 2009). Furthermore, potentiometric titrations showed that PAMAM dendrimers carry positive charges on their peripheral groups at physiological $\mathrm{pH}$ (Cakara et al. 2003) which leads to cytotoxicity response (Mukherjee et al. 2010a, b), but the systemic modification of surface groups (e.g., hydroxylation, acetylation, PEGylation) could resolve this problem (Jain et al. 2010; Svenson 2009; Shi et al. 2006; Kolhatkar et al. 2007). The polyester dendrimers based on 2,2-bis(hydroxymethyl)propionic acid (bis-MPA) monomers (Ihre et al. 1996) are biodegradable and biocompatible with very low toxicity and low immunogenicity (Feliu et al. 2012; Ihre et al. 2002). Therefore, several biomedical applications have been proposed for polyester dendrimers in pre-clinical studies (Stenström 2020).

Favipiravir, known as T705, has been developed by Toyama Chemical Co., Ltd., in Japan as an antiinfluenza drug (Shiraki and Daikoku 2020). This drug functions as a chain terminator at the site of incorporation of the viral RNA and reduces the viral load (Furuta et al. 2005). Although T705 was originally developed to treat influenza, it has a wide range of activities toward RNA viruses and has been used for treatment of Ebola virus (Bai et al. 2016), Lassa virus (Oestereich et al. 2016), and severe fever with thrombocytopenia syndrome (Tani et al. 2016). Favipiravir does not produce resistant viruses, therefore, preserves its treatment efficacy during influenza pandemic or an epidemic lethal RNA virus infection (Shiraki and Daikoku 2020). Favipiravir is currently undergoing clinical studies as an important therapeutic agent for coronavirus (Dong et al. 2020; Li and Clercq 2019).
In spite of the medicinal relevance of PAMAM and polyester dendrimers, few studies have been devoted to the atomic-level interactions between these nanostructures and drug molecules. Recently, we have studied the complexation of nicotinic acid (NA) with first-generation PAMAM dendrimers (BadalkhaniKhamseh et al. 2017b) and demonstrated that the stability of PAMAM-NA could be attributed to the partially covalent interactions. In another work, the host-guest interactions between polyester dendrimers and ibuprofen was explored using DFT calculations (Bazyari-Delavar et al. 2020). However, a comparative quantum mechanical investigation on the mechanism of interaction between PAMAM and polyester dendrimers with a drug molecule is still lacking.

Given the aforementioned challenges and opportunities, we applied first-principle computations to inspect PAMAM and polyester dendrimers as T705 nanocarriers. Density functional theory (DFT)-based calculations can deliver comprehensive atomic-level information on the changes of structural geometries, interaction energies, charge distribution, and steric effects under encapsulation process. Therefore, first-principle investigations may provide a more object-oriented approach of study for experimental researches. We report the results using a number of analyses such as geometry optimization, vibrational frequencies, density of stated (DOS), and natural bond orbitals (NBO).

\section{Theoretical methods}

DFT is a type of electronic structure calculation that has become a powerful tool for defining intermolecular interactions (Karimzadeh et al. 2021). It is wellknown that intermolecular interactions are of great relevance in chemical reactions and are used in the calculation of energy gap, electronic properties of semiconductors, frontier molecular orbital analysis, and interaction energies (Piela 2013). Gaussian is one of the powerful tools in the prediction of the electronic structure of molecules and explains the reaction mechanism, energy gap, atomic charges, electronegativity, and thermochemical properties precisely and, therefore, was applied in this work (Karimzadeh et al. 2020). Full geometry optimizations were performed using M06-2X density functional approach in conjunction with 6-31G(d,p) basis set as implemented in 
Gaussian 09 W software package (Zhao and Truhlar 2008; Schmidt et al. 1993). The M06-2X functional is a hybrid meta-GGA exchange-correlation functional parameterized for nonmetals. This functional is recommended for application in main group thermochemistry, thermochemical kinetics, noncovalent interactions, and excited states (Grimme 2011). To ensure that all optimized structures are the true stationary points on the potential energy surface (PES), vibrational frequency calculations were performed using the same method and basis set. Also, vibrational frequencies provide us with the zero-point vibrational energies for determining the enthalpy changes upon encapsulation process and Gibbs free energy. Equation (1) shows the definition used to calculate the enthalpy changes at $\mathrm{T}=298 \mathrm{~K}$ and $\mathrm{P}=1 \mathrm{~atm}$ :

$\Delta H=\Delta H_{\text {complex }}-\left(\Delta H_{\text {dendrimer }}+\Delta H_{\text {drug }}\right)$

The Gibbs free energy changes $(\Delta \mathrm{G})$ and the binding energy $\left(\mathrm{E}_{\text {binding }}\right)$ of complexation process were also obtained using the similar equations at the same conditions. To mimic the experimental conditions more accurately, we considered solvent effects implicitly $\left(\varepsilon_{\text {water }}=78.36\right)$ making use of the PCM model, which is the default SCRF method in Gaussian package. As mentioned before, all amine groups located at the surface of PAMAM dendrimer are protonated at neutral $\mathrm{pH}$ conditions. The $\mathrm{pK}_{\mathrm{a}}$ value of T705 is reported to be 5.1 and therefore has no charge at solvent phase (Jain and Barhate 2021). Natural bond orbital (NBO) (Reed et al. 1988) analyses were performed to describe hybridization and covalency effects and to represent a chemical interpretation the bonding in the case of van der Waals interactions. The gaps in the energy levels $\left(\mathrm{E}_{\mathrm{g}}\right)$ of a system is given as

$E_{g}=E_{\text {LUMO }}-E_{\text {НОМО }}$

in which $\mathrm{E}_{\mathrm{LUMO}}$ is the energy of lowest unoccupied molecular orbital and $\mathrm{E}_{\mathrm{HOMO}}$ is the energy of the highest occupied molecular orbital. The density of states (DOS) of a system shows the density per unit volume and energy of the number of solutions to Schrödinger's equation. In an isolated system, energy levels are discrete, and the concept of DOS is not clear. However, if discrete energy levels are artificially expanded to the curve, DOS diagram can act a powerful tool to explain the composition of orbitals
(Zhong et al. 2016). Partial density of states (PDOS) function of fragment A is stated as follows:

$\operatorname{PDOS}_{A}(E)=\sum_{i} E_{i, A} F\left(E-\varepsilon_{i}\right)$

In this equation, $\mathrm{E}_{i, \mathrm{~A}}$ is the composition of orbital $\mathrm{i}$ and fragment $\mathrm{A}$, and $\varepsilon_{i}$ shows the single-particle Hamilton eigenvalue set (Marston and Balint-Kurti 1989). GaussSum program (O'boyle et al. 2008) was used to obtain the PDOS results.

\section{Results and discussion}

Geometrical structure and electronic properties

The optimized geometries of PAMAM and polyester dendrimers are shown in Figs. 1a and 2a, respectively. In the case of PAMAM dendrimer, the computed vibrational frequencies are in the range of 3-3683 $\mathrm{cm}^{-1}$, demonstrating that the optimized structure corresponds to the true stationary points on the potential energy surface. The average lengths of $\mathrm{C}-\mathrm{C}, \mathrm{C}-\mathrm{N}, \mathrm{C}-\mathrm{C}_{\text {carbonyl }}, \mathrm{C}=\mathrm{O}, \mathrm{C}-\mathrm{N}_{\text {peripheral }}$, and $\mathrm{C}_{\text {carbonyl }}-\mathrm{N}$ are predicted to be $1.529,1.456,1.515$, $1.229,1.500$, and $1.356 \AA$, respectively. The HOMO and LUMO energies in solvent phase are equal to -7.63 and $1.13 \mathrm{eV}$, respectively; and therefore, the $\mathrm{E}_{\mathrm{g}}$ value is about $8.76 \mathrm{eV}$ (Table 1). The HOMO-LUMO energy gap is an index of kinetic stability, and the lower value indicates higher reactivity in the solvent phase. The $\mathrm{E}_{\mathrm{HOMO}}$ and $\mathrm{E}_{\mathrm{LUMO}}$ values in gas phase are about -7.41 and $1.54 \mathrm{eV}$, which according to Eq. (2) gives an $\mathrm{E}_{\mathrm{g}}$ value of $8.95 \mathrm{eV}$.

In the case of polyester dendrimer, the calculated minimum and maximum vibrational frequencies are 19 and $3900 \mathrm{~cm}^{-1}$, respectively. The average $\mathrm{C}-\mathrm{C}_{\text {hydroxyl }}, \mathrm{C}-\mathrm{C}_{\text {ester }}, \mathrm{C}-\mathrm{O}, \mathrm{C}-\mathrm{O}_{\text {ester }}, \mathrm{C}=\mathrm{O}$, and $\mathrm{O}-\mathrm{H}$ bond lengths are about 1.539, 1.515, 1.413, $1.436,1.13$, and $0.971 \AA$, respectively. The HOMO and LUMO energy values in the gas phase are predicted to be -8.98 and $0.40 \mathrm{eV}$, respectively, producing an $\mathrm{E}_{\mathrm{g}}$ value of $9.38 \mathrm{eV}$. The $\mathrm{E}_{\mathrm{HOMO}}$ and $\mathrm{E}_{\mathrm{LUMO}}$ values shift -9.16 and $0.77 \mathrm{eV}$, respectively, upon considering implicit solvent effects. Thus, the $\mathrm{E}_{\mathrm{g}}$ is increased by about 5.8\% from 9.38 to $9.93 \mathrm{eV}$.

The T705 drug (Fig. 3a) has a carbonyl (O9) and a hydroxyl (O8) oxygen, an amino nitrogen (N3), and a fluoro (F14) group act as electron donating 

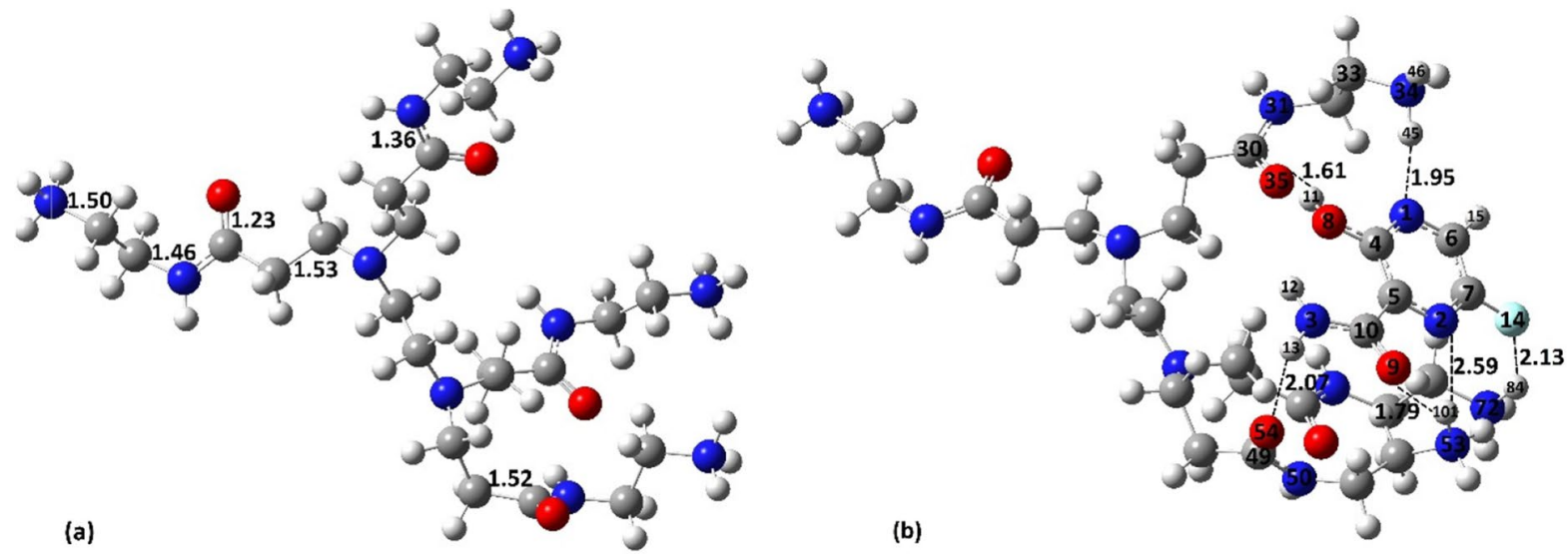

Fig. 1 Optimized structures of a PAMAM and b PAMAM-T705 complex. Distances are in $\AA$. Atom colors: carbon in gray, nitrogen in blue, oxygen in red, and hydrogen in white
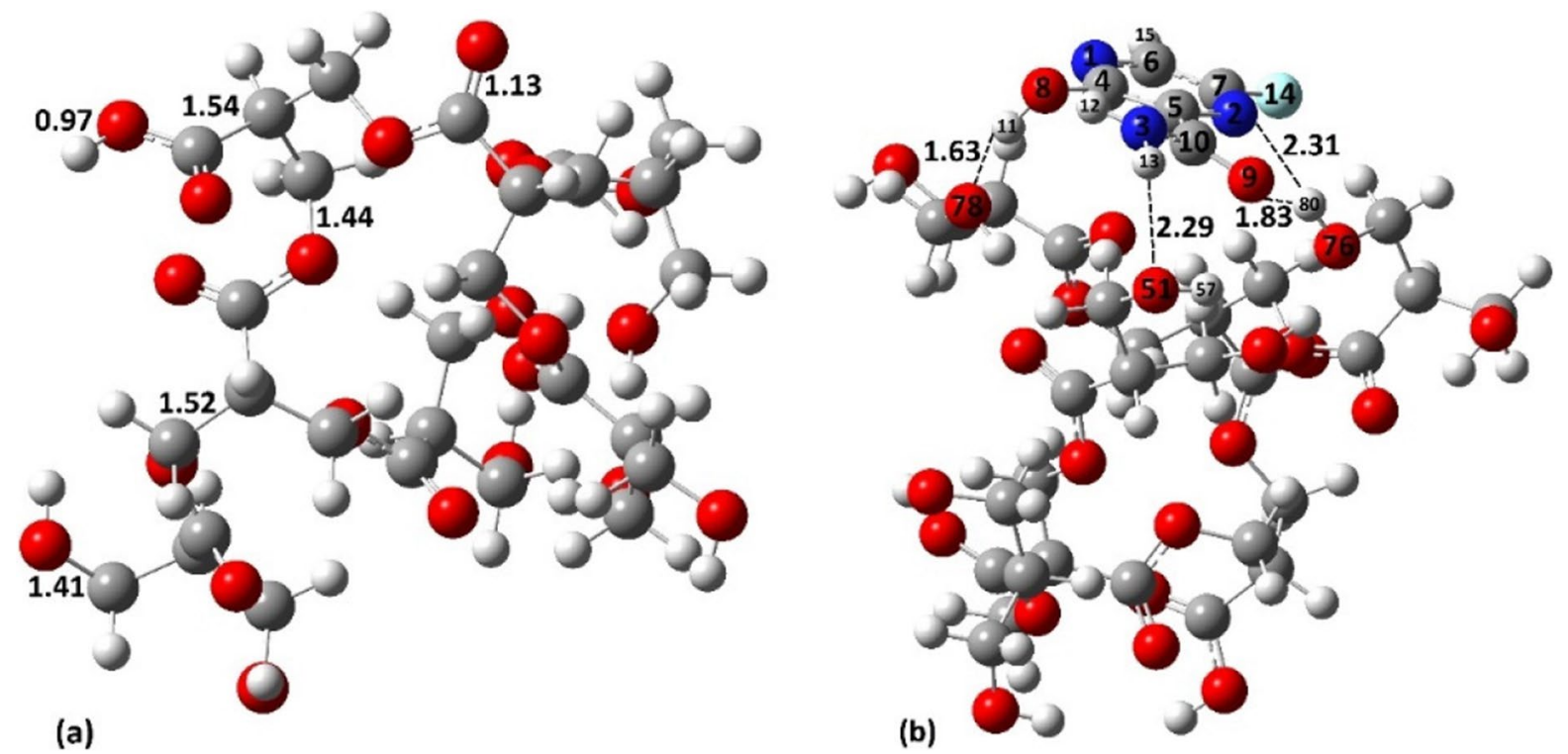

Fig. 2 Optimized structures of a polyester and b polyester-T705 complex. Distances are in $\AA$. Atom colors: carbon in gray, nitrogen in blue, oxygen in red, fluorine in cyan, and hydrogen in white

agents. The HOMO level of T705 is mostly located on hydroxyl oxygen and 6-membered ring, indicating that these groups are potential candidates for interaction with functional groups of PAMAM and polyester dendrimers. Moreover, the molecular electrostatic potential (MEP) profile of T705 (Fig. 3c) shows that oxygen of carbonyl group has the most negative electrostatic potential in this structure.
The adsorption of T705 on the PAMAM and polyester dendrimers

To find the most stable complexes of PAMAM-T705 and polyester-T705, we considered all probable orientations for T705 with each functional group regarding the MEP profiles of interacting species as shown in Figs. $3 \mathrm{c}$ and 4. 
Table 1 The values of

$\mathrm{E}_{\text {HOMO }}, \mathrm{E}_{\mathrm{LuMO}}, \mathrm{E}_{\mathrm{g}}$, work function $(\Phi)$, energy of Fermi level $\left(\mathrm{E}_{\mathrm{F}}\right)$, and quantum molecular descriptors of the most stable complexes calculated at M06-2X/6-31G (d,p) level of theory. All parameters are in $\mathrm{eV}$

${ }^{a}$ Changes of $E_{g}$ after the T705 encapsulation.

\begin{tabular}{|c|c|c|c|c|c|c|c|c|c|}
\hline Configuration & & $\mathrm{E}_{\text {Номо }}$ & $\mathrm{E}_{\text {LUMO }}$ & $E_{g}$ & $\Delta \mathrm{E}_{\mathrm{g}}(\%)^{\mathrm{a}}$ & $\Phi\left(-\mathrm{E}_{\mathrm{F}}\right)$ & $\mu$ & $\eta$ & $\omega$ \\
\hline T705 & Gas & -8.45 & -1.15 & 7.30 & & 4.80 & -4.80 & 3.65 & 3.16 \\
\hline PAMAM & & -7.41 & 1.54 & 8.95 & & 2.94 & -2.94 & 4.48 & 0.96 \\
\hline PAMAM-T705 & & -7.45 & -1.08 & 6.37 & -29 & 4.27 & -4.27 & 3.19 & 2.86 \\
\hline Polyester & & -8.98 & 0.40 & 9.38 & & 4.26 & -4.26 & 4.66 & 1.95 \\
\hline Polyester-T705 & & -8.61 & -1.37 & 7.24 & -23 & 4.99 & -4.99 & 3.62 & 3.44 \\
\hline T705 & Solvent & -8.43 & -1.14 & 7.29 & & 4.79 & -4.79 & 3.65 & 3.14 \\
\hline PAMAM & & -7.63 & 1.13 & 8.76 & & 3.25 & -3.25 & 4.38 & 1.21 \\
\hline PAMAM-T705 & & -7.74 & -1.81 & 5.93 & -32 & 4.78 & -4.78 & 2.97 & 3.85 \\
\hline Polyester & & -9.16 & 0.77 & 9.93 & & 4.20 & -4.20 & 4.97 & 1.77 \\
\hline Polyester-T705 & & -8.53 & -1.28 & 7.25 & -27 & 4.91 & -4.91 & 3.63 & 3.32 \\
\hline
\end{tabular}

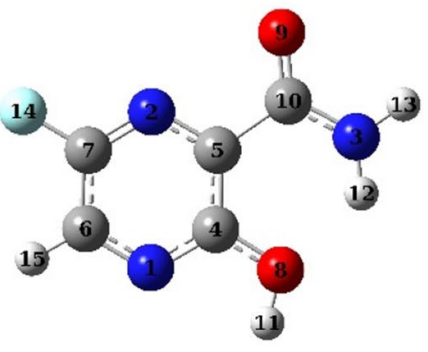

(a)

Fig. 3 (a) Optimized structure of T705, b HOMO, and c computed electrostatic potentials on the molecular surfaces of (MEP) of T705. The surfaces are specified by the 0.0004 electrons/b3 contour of the electronic density. Color ranges, in a.u.:

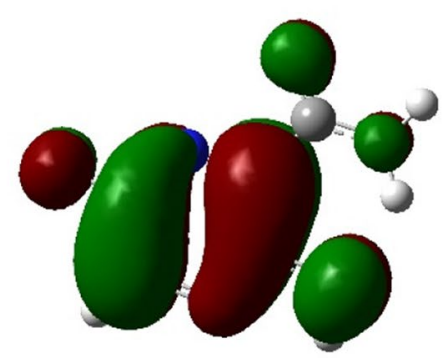

(b)

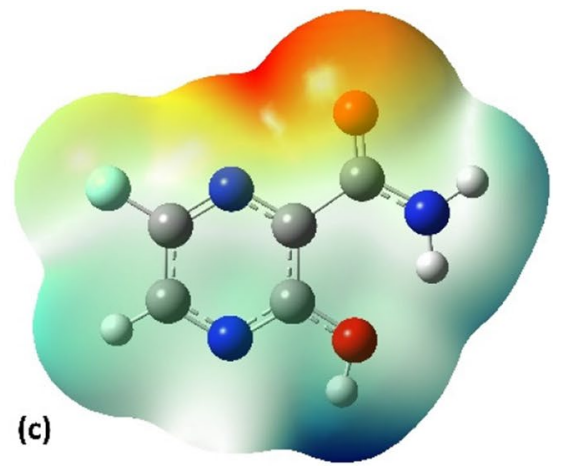

blue, more positive than 0.010 ; green, between 0.010 and 0 ; yellow, between 0 and -0.010 ; red, more negative than -0.010 . Atom colors: carbon in gray, nitrogen in blue, oxygen in red, fluorine in cyan, and hydrogen in white

Fig. 4 Computed electrostatic potentials on the molecular surfaces of (MEP) of a PAMAM and $\mathbf{b}$ polyester dendrimers. Atom colors: carbon in gray, nitrogen in blue, oxygen in red, and hydrogen in white

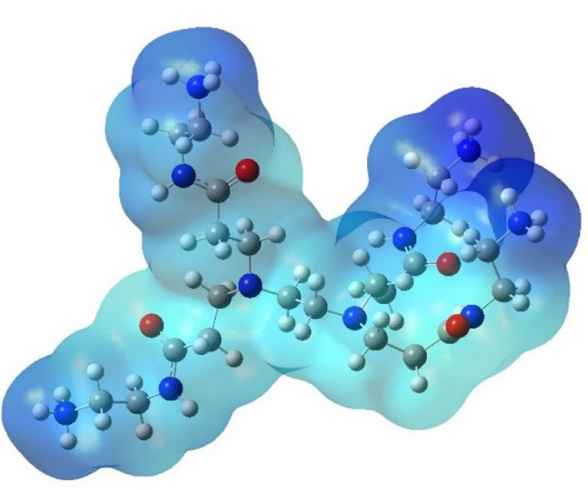

(a)

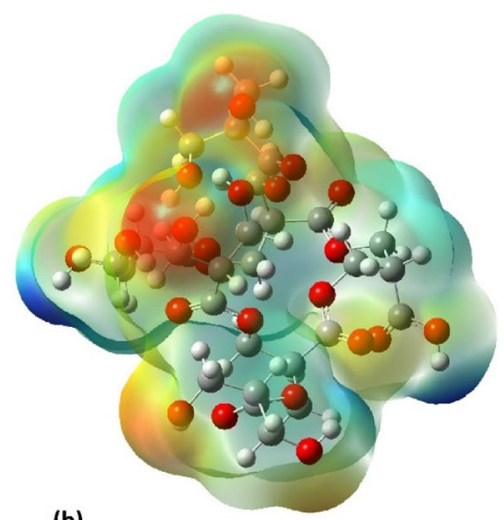

(b)
After full optimization of all configurations followed by vibrational frequency calculations, we found that T705 molecule prefers to be adsorbed on the surface of PAMAM and polyester dendrimers via its $\mathrm{N}_{\text {ring }}, \mathrm{C}=\mathrm{O}, \mathrm{OH}$, and $\mathrm{NH}_{2}$ groups (Figs. $1 \mathrm{~b}$ and $2 \mathrm{~b}$ ). Shown in Table 2 are some of calculated energetic data $(\Delta \mathrm{H}, \Delta \mathrm{G}$, and binding energies $\left.\left(\mathrm{E}_{\text {binding }}\right)\right)$ and minimum and maximum 
Table 2 Calculated energetic data $\left(\Delta \mathrm{H}, \Delta \mathrm{G}\right.$, and binding energies $\left(\mathrm{E}_{\mathrm{binding}}\right)$ in $\left.\mathrm{kcal} \mathrm{mol} \mathrm{m}^{-1}\right)$, minimum and maximum modes of vibrational frequencies $\left(\nu_{\min }\right.$ and $\nu_{\max }$ in $\left.\mathrm{cm}^{-1}\right)$ for complexes at M06-2X/6-31G $(\mathrm{d}, \mathrm{p})$

\begin{tabular}{lllllrr}
\hline Configuration & & $\Delta \mathrm{H}$ & $\Delta \mathrm{G}$ & $\mathrm{E}_{\mathrm{b}}$ & $\nu_{\min }$ & $\nu_{\max }$ \\
\hline PAMAM-T705 & Gas & -27.70 & -12.54 & -36.65 & 10 & 3713 \\
& Solvent & -25.88 & -7.91 & -27.26 & 12 & 3701 \\
Polyester-T705 & Gas & -29.68 & -14.83 & -31.64 & 16 & 3917 \\
& Solvent & -17.46 & -5.92 & -26.80 & 16 & 3903 \\
\hline
\end{tabular}

modes of vibrational frequencies $\left(\nu_{\min }\right.$ and $\left.\nu_{\max }\right)$ for PAMMA- and polyester-T705 complexes. The binding energy of PAMAM-T705 complex is about $-27.26 \mathrm{kcal} \mathrm{mol}^{-1}$ in the solvent phase, with a charge transfer of 0.03 lel from T705 molecule (donor) to PAMAM dendrimer (acceptor). After T705 adsorption, the HOMO of PAMAM does not change considerably, but the LUMO level is highly stabilized by going from 1.13 to $-1.81 \mathrm{eV}$. Consequently, the $\mathrm{E}_{\mathrm{g}}$ of the PAMAM dendrimer decreases by about $32 \%$ upon T705 drug adsorption.
The most important computed geometrical parameters of T705 and PAMAM dendrimer before and after adsorption process are tabulated in Table 3.

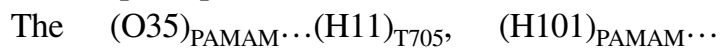

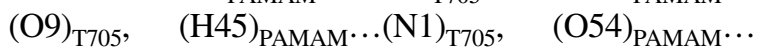
$(\mathrm{H} 13)_{\mathrm{T} 705}, \quad(\mathrm{H} 84)_{\text {PAMAM }} . .(\mathrm{F} 14)_{\mathrm{T} 705}, \quad$ and $(\mathrm{H} 101)_{\text {PAMAM }} \ldots(\mathrm{N} 2)_{\mathrm{T} 705}$ interaction distances are about $1.61,1.79,1.95,2.07,2.13$, and $2.59 \AA$, respectively. Three first interaction distances indicate that the hydroxyl, carbonyl, and $\mathrm{N} 1_{\text {ring }}$ of $\mathrm{T} 705$ are more reactive toward PAMAM than the amino group. This could be attributed to the less steric hindrance and
Table 3 Selected optimized geometrical parameters of PAMAM dendrimer and T705 before and after complexation calculated at the M06-2X/6$31 \mathrm{G}(\mathrm{d}, \mathrm{p})$ level of theory in solvent phase. The values in parentheses represent the data before adsorption process

\begin{tabular}{|c|c|c|c|c|}
\hline & Parameter & Bond length $(\AA)$ & Parameter & Bond angle $\left({ }^{\circ}\right)$ \\
\hline \multirow[t]{14}{*}{ T705 } & $\mathrm{N} 1-\mathrm{C} 4$ & $1.336(1.329)$ & $\mathrm{N} 1-\mathrm{C} 4-\mathrm{O} 8$ & $119.1(117.1)$ \\
\hline & $\mathrm{C} 4-\mathrm{C} 5$ & $1.410(1.408)$ & $\mathrm{C} 4-\mathrm{O} 8-\mathrm{H} 11$ & $109.7(108.3)$ \\
\hline & $\mathrm{N} 2-\mathrm{C} 5$ & $1.334(1.336)$ & $\mathrm{C} 5-\mathrm{C} 4-\mathrm{O} 8$ & $120.1(120.7)$ \\
\hline & $\mathrm{N} 2-\mathrm{C} 7$ & $1.306(1.305)$ & $\mathrm{C} 4-\mathrm{C} 5-\mathrm{C} 10$ & $125.6(126.5)$ \\
\hline & $\mathrm{C} 6-\mathrm{C} 7$ & $1.390(1.393)$ & $\mathrm{C} 5-10-\mathrm{O} 9$ & $118.8(119.7)$ \\
\hline & $\mathrm{C} 7-\mathrm{F} 14$ & $1.341(1.333)$ & $\mathrm{C} 5-\mathrm{C} 10-\mathrm{N} 3$ & $118.1(117.0)$ \\
\hline & C6-H15 & 1.085 (1.085) & $\mathrm{C} 10-\mathrm{N} 3-\mathrm{H} 12$ & $121.5(122.9)$ \\
\hline & $\mathrm{C} 5-\mathrm{C} 10$ & $1.513(1.519)$ & $\mathrm{C} 10-\mathrm{N} 3-\mathrm{H} 13$ & $116.9(117.3)$ \\
\hline & $\mathrm{O} 9-\mathrm{C} 10$ & 1.235 (1.222) & $\mathrm{N} 3-\mathrm{C} 10-\mathrm{O} 9$ & $123.0(123.3)$ \\
\hline & $\mathrm{N} 3-\mathrm{C} 10$ & $1.331(1.346)$ & $\mathrm{N} 2-\mathrm{C} 5-\mathrm{C} 4$ & $120.0(118.9)$ \\
\hline & N3-H12 & $1.010(1.008)$ & $\mathrm{C} 5-\mathrm{N} 2-\mathrm{C} 7$ & $117.6(118.0)$ \\
\hline & N3-H13 & $1.016(1.009)$ & $\mathrm{N} 2-\mathrm{C} 7-\mathrm{C} 6$ & $123.7(123.5)$ \\
\hline & $\mathrm{C} 4-\mathrm{O} 8$ & $1.328(1.344)$ & $\mathrm{N} 2-\mathrm{C} 7-\mathrm{F} 14$ & $116.9(117.4)$ \\
\hline & O8-H11 & $0.995(0.970)$ & $\mathrm{C} 4-\mathrm{N} 1-\mathrm{C} 6$ & $118.6(118.0)$ \\
\hline \multirow[t]{9}{*}{ PAMAM } & $\mathrm{C} 30-\mathrm{N} 31$ & $1.341(1.358)$ & $\mathrm{N} 31-\mathrm{C} 30-\mathrm{O} 35$ & $120.67(121.3)$ \\
\hline & $\mathrm{C} 30-\mathrm{O} 35$ & $1.239(1.227)$ & $\mathrm{C} 29-\mathrm{C} 30-\mathrm{O} 35$ & $120.6(122.8)$ \\
\hline & C33-N34 & $1.495(1.500)$ & C33-N34-H45 & $109.1(111.8)$ \\
\hline & N34-H45 & $1.041(1.024)$ & $\mathrm{N} 50-\mathrm{C} 49-\mathrm{O} 54$ & $123.0(121.8)$ \\
\hline & $\mathrm{N} 34-\mathrm{H} 46$ & $1.023(1.024)$ & C49-N50-C51 & $122.1(119.7)$ \\
\hline & $\mathrm{C} 49-\mathrm{N} 50$ & 1.353 (1.359) & C51-C52-N53 & $109.8(110.7)$ \\
\hline & $\mathrm{C} 49-\mathrm{O} 54$ & $1.232(1.228)$ & C52-N53-H101 & $106.8(111.8)$ \\
\hline & N53-H101 & $1.041(1.024)$ & C71-N72-H84 & $110.1(111.0)$ \\
\hline & N72-H84 & 1.025 (1.024) & $\mathrm{C} 70-\mathrm{C} 71-\mathrm{N} 72$ & $111.7(110.6)$ \\
\hline
\end{tabular}


localization of HOMO level around the mentioned groups (Fig. 3b). Optimized geometry of PAMAMT705 complex revealed that no substantial changes have occurred in the bond lengths of PAMAM dendrimer upon encapsulation. The most important changes in PAMAM bond lengths are elongation of $\mathrm{C} 30-\mathrm{O} 35, \mathrm{~N} 53-\mathrm{H} 101$, and $\mathrm{N} 34-\mathrm{H} 45$ by about $0.01,0.02$, and 0.02 , respectively, and shortening of C30-N31 by about $0.02 \AA$. The structural parameters of T705 and polyester dendrimer before and after complexation are shown in Table 4. Same as PAMAM dendrimer, geometrical changes of T705 upon adsorption process are insignificant. The $\mathrm{N} 1-\mathrm{C} 4, \mathrm{O} 9-\mathrm{C} 10$, N3-H13, and C7-F14 bond lengths increase by about $0.01 \AA$. The increase of O8-H11 bond length $(0.03 \AA)$ along with the decrease of $\mathrm{C} 4-\mathrm{O} 8(0.02 \AA)$ is the most prominent changes indicating that a relatively strong interaction happens between carbonyl group located at the surface residue of PAMAM and hydroxyl group of T705. The binding energy of polyester-T705 complex has the value of $-26.80 \mathrm{kcal} \mathrm{mol}^{-1}$ in solvent, which is close to the $\mathrm{E}_{\text {binding }}$ of PAMAM-T705 complex. The NBO analysis shows that a charge transfer of 0.01 le takes place from polyester dendrimer (donor) to the drug molecule (acceptor). The eminent interaction distances are $(\mathrm{O} 78)_{\text {polyester }} \ldots(\mathrm{H} 11)_{\mathrm{T} 705},(\mathrm{H} 80)_{\text {polyester }} \cdots$

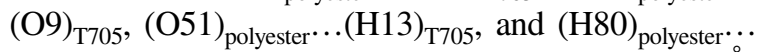
$(\mathrm{N} 2)_{\mathrm{T} 705}$ with the values of $1.63,1.83,2.29$, and $2.31 \AA$, respectively (Fig. 2b). These distances are reasonable for intermolecular interactions between peripheral $\mathrm{OH}$ groups of polyester dendrimer and functional groups of T705. Despite the strong interaction energy value, bond lengths in polyester dendrimer and T705 molecule remain almost constant except for $\mathrm{C} 4-\mathrm{O} 8$ bond length changed by about $+0.03 \AA$.

\section{Electrical conductivity}

The sensing mechanism of an adsorbent is connected to the change of its electrical conductance upon drug adsorption. The $\mathrm{E}_{\mathrm{g}}$ is a value of kinetic stability and, based on the following equation, is an electronic parameter determine sensitivity of the carrier toward cargo:

$\sigma=A T^{3} / 2 \exp \left(-E_{g} / 2 k T\right)$

where $\mathrm{A}$ is a constant in electrons $/ \mathrm{m}^{3} \mathrm{~K}^{3 / 2}$ and $\mathrm{k}$ is the Boltzmann's constant. Based on Eq. (4), the electrical conductivity of a drug carrier increases
Table 4 Selected optimized geometrical parameters of polyester dendrimer and $\mathrm{T} 705$ before and after complexation calculated at the M06-2X/6$31 \mathrm{G}(\mathrm{d}, \mathrm{p})$ level of theory in solvent phase. The values in parentheses represent the data before adsorption process

\begin{tabular}{lllll}
\hline & Parameter & Bond length $(\AA)$ & Parameter & Bond angle $\left(^{\circ}\right)$ \\
\hline T705 & N1-C4 & $1.332(1.329)$ & N1-C4-O8 & $117.7(117.1)$ \\
C4-C5 & $1.406(1.408)$ & C4-O8-H11 & $108.2(108.3)$ \\
N2-C5 & $1.337(1.336)$ & C5-C4-O8 & $121.009(120.7)$ \\
N2-C7 & $1.304(1.305)$ & C4-C5-C10 & $125.0(126.5)$ \\
C6-C7 & $1.394(1.393)$ & C5-10-O9 & $119.2(119.7)$ \\
C7-F14 & $1.336(1.333)$ & C5-C10-N3 & $118.1(117.0)$ \\
C6-H15 & $1.085(1.085)$ & C10-N3-H12 & $119.3(122.9)$ \\
C5-C10 & $1.511(1.519)$ & C10-N3-H13 & $115.1(117.3)$ \\
O9-C10 & $1.233(1.222)$ & N3-C10-O9 & $122.8(123.3)$ \\
N3-C10 & $1.339(1.346)$ & N2-C5-C4 & $120.2(118.9)$ \\
N3-H12 & $1.011(1.008)$ & C5-N2-C7 & $117.0(118.0)$ \\
N3-H13 & $1.013(1.009)$ & N2-C7-C6 & $123.7(123.5)$ \\
Polyester & $1.345(1.344)$ & N2-C7-F14 & $117.3(117.4)$ \\
& O8-H11 & $1.002(0.970)$ & C4-N1-C6 & $118.0(118.0)$ \\
C48-O51 & $1.408(1.409)$ & C48-O51-H57 & $106.1(104.6)$ \\
O51-H57 & $0.974(0.970)$ & C46-C48-O51 & $112.3(111.0)$ \\
C71-O76 & $1.412(1.412)$ & C71-O76- H80 & $111.8(108.4)$ \\
O76-H80 & $0.978(0.977)$ & C69-C71-O76 & $107.9(111.8)$ \\
C74-O78 & $1.419(1.419)$ & C74-O78- H82 & $106.9(105.4)$ \\
O78-H82 & $0.975(0.973)$ & C72-C74-O78 & $113.3(113.6)$ \\
\hline
\end{tabular}


exponentially with a decrease of $\mathrm{E}_{\mathrm{g}}$ value, which is converted to an electrical signal in the presence of drug. Therefore, it is important to explore the change of $\mathrm{E}_{\mathrm{g}}$ value upon drug adsorption as it alters the fluorescence emission of nanostructures and helps us to recognize the attachment of the cargo to the carrier and to trace the trajectory of drug in the body using the spectrophotometers (Hazrati et al. 2017).

Table 1 exhibits that $\mathrm{E}_{\mathrm{HOMO}}, \mathrm{E}_{\mathrm{LUMO}}$, and $\mathrm{E}_{\mathrm{g}}$ of PAMAM and polyester dendrimers are sensibly affected by complexation process. Shown in Fig. 5 is the partial density of states (PDOS) plot of PAMAMT705 complex indicating that two new states have appeared at -0.41 and $-1.81 \mathrm{eV}$ energy levels upon drug molecule adsorption onto the PAMAM dendrimer surface, which are mainly originated from T705. Figure $6 \mathrm{a}-\mathrm{d}$ indicates that the LUMO profile is significantly altered by T705 complexation into PAMAM dendrimer. The HOMO and LUMO levels of PAMAM (Fig. 6a and b) are mostly localized on
Fig. 5 Partial density of states (PDOS) of PAMAMT705 complex in solvent phase

Fig. 6 (a) HOMO of PAMAM, b LUMO of PAMAM, $\mathbf{c}$ HOMO of PAMAM-T705, and d LUMO of PAMAM-T705. Atom colors: carbon in gray, nitrogen in blue, oxygen in red, fluorine in cyan, and hydrogen in white

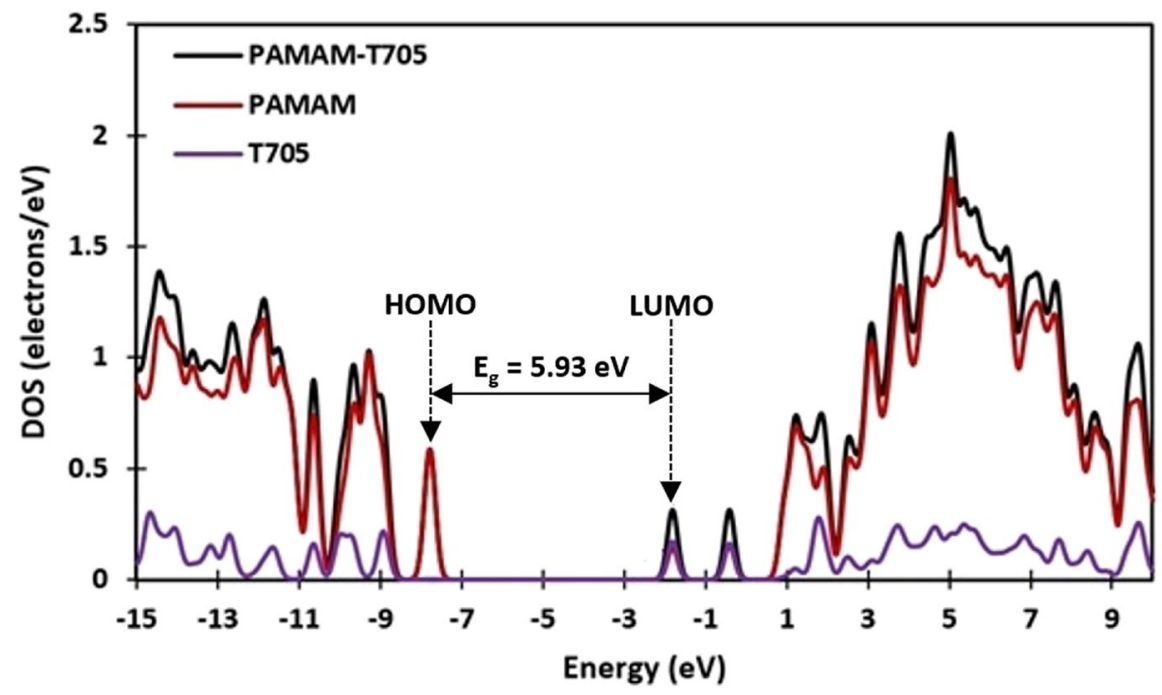

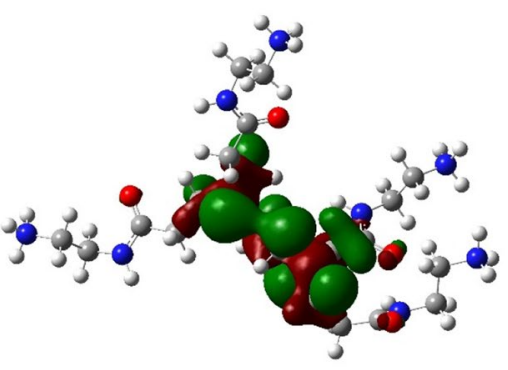

(a)

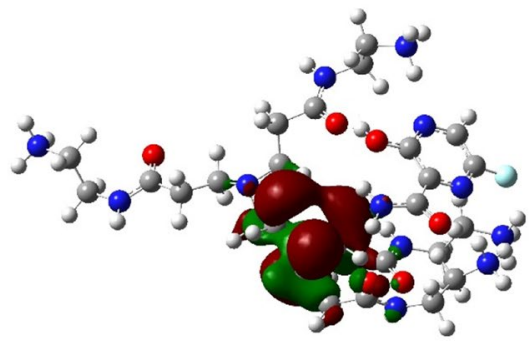

(c)

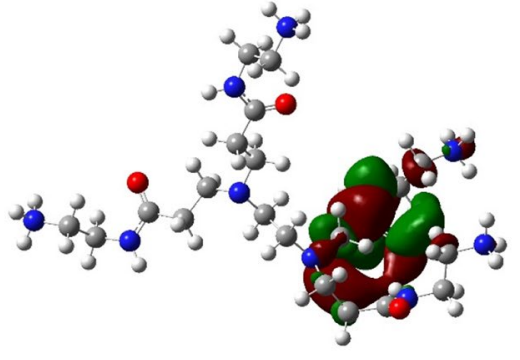

(b)

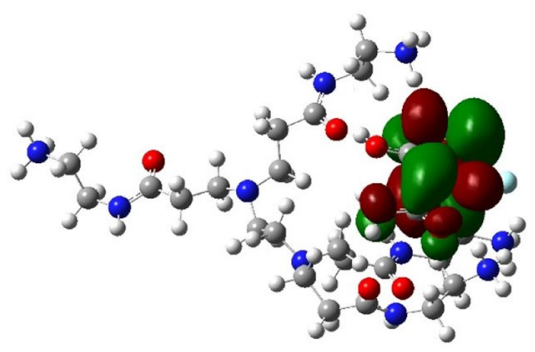

(d) 
the core and peripheral residues, respectively. After interaction with T705, HOMO is still located on the core residue of PAMAM, but the LUMO level shifts from PAMAM to the drug molecule. In the case of polyester dendrimer, the HOMO and LUMO of polyester-T705 complex change from -9.16 and $0.77 \mathrm{eV}$ in the bare dendrimer to -8.53 and $-1.28 \mathrm{eV}$ in the complex, respectively, narrowing the $\mathrm{E}_{\mathrm{g}}$ by about $2.68 \mathrm{eV}$.

As shown in Fig. 7, adsorption of T705 on the polyester dendrimer causes three new electron state to be appeared at $0.07,-1.28$, and $-8.53 \mathrm{eV}$ mainly come from the T705 molecule. In accordance with these energy changes, HOMO and LUMO profiles of polyester dendrimer (Fig. 8a and b) shift from the polyester surface to the drug molecule after adsorption.

To predict the magnitude of electrical change of PAMAM and polyester dendrimers under the adsorption of T705 molecule, one can write:

$\frac{\sigma_{2}}{\sigma_{1}}=\exp \left[\frac{-\left(E_{g_{2}}-E_{g_{1}}\right)}{2 k T}\right]$

In Eq. (5), 1 and 2 subscripts show PAMAM/ polyester dendrimers and their complexes with T705 drug molecule, respectively, and kT is about $0.0257 \mathrm{eV}$ at $298 \mathrm{~K}$. Considering the $E_{g_{2}}-E_{g_{1}}$ values of the investigated structures $(-2.83 \mathrm{eV}$ in PAMAM and -2.68 in polyester), we find that $\sigma_{2}=8.16 \times 10^{23}$ $\sigma_{1}$ for PAMAM and $\sigma_{2}=4.41 \times 10^{22} \sigma_{1}$ for polyester dendrimer. Therefore, the electrical conductance of PAMAM and polyester dendrimers become
$8.16 \times 10^{23}$ and $4.41 \times 10^{22}$ times higher, respectively, upon T705 adsorption indicating that these nanostructures are proper sensors for T705 detection. However, the following points should be taken into consideration before confirming the PAMAM and polyester dendrimers as T705 detectors. The adsorption of T705 reduces the energy gap of PAMAM and polyester dendrimers considerably, but the energy gap of PAMAM-t705 and polyester-T705 is about 6 and $7 \mathrm{eV}$, respectively, meaning that the thermal energy at $300 \mathrm{~K}(\sim 25 \mathrm{meV})$ is insufficient to allow electrons from the valence band to be promoted to the conduction band. It is proposed to use some energy gap enlarging methods like surface modification to reduce the energy gap of dendrimers.

Adsorption process also affects the Fermi level of work function type ( $\Phi$-type) sensors. The $\Phi$-type sensor applies a Kelvin oscillator instrument to calculate the values of $\Phi$ before and after adsorption process (Hosseinian et al. 2017). When a chemical agent is adsorbed by a $\Phi$-type sensor, the gate voltage of adsorbent changes; therefore, an electrical signal is created detecting the presence of adsorbed molecule. The $\Phi$ value is considered as the minimum amount of energy needed to induce electron emission from the Fermi level:

$\Phi=V_{e l(+\infty)}-E_{F}$

where $E_{F}$ is the Fermi level energy and $V_{e l(+\infty)}$ is the electron electrostatic potential energy far from
Fig. 7 Partial density of states (PDOS) of polyesterT705 complex in solvent phase

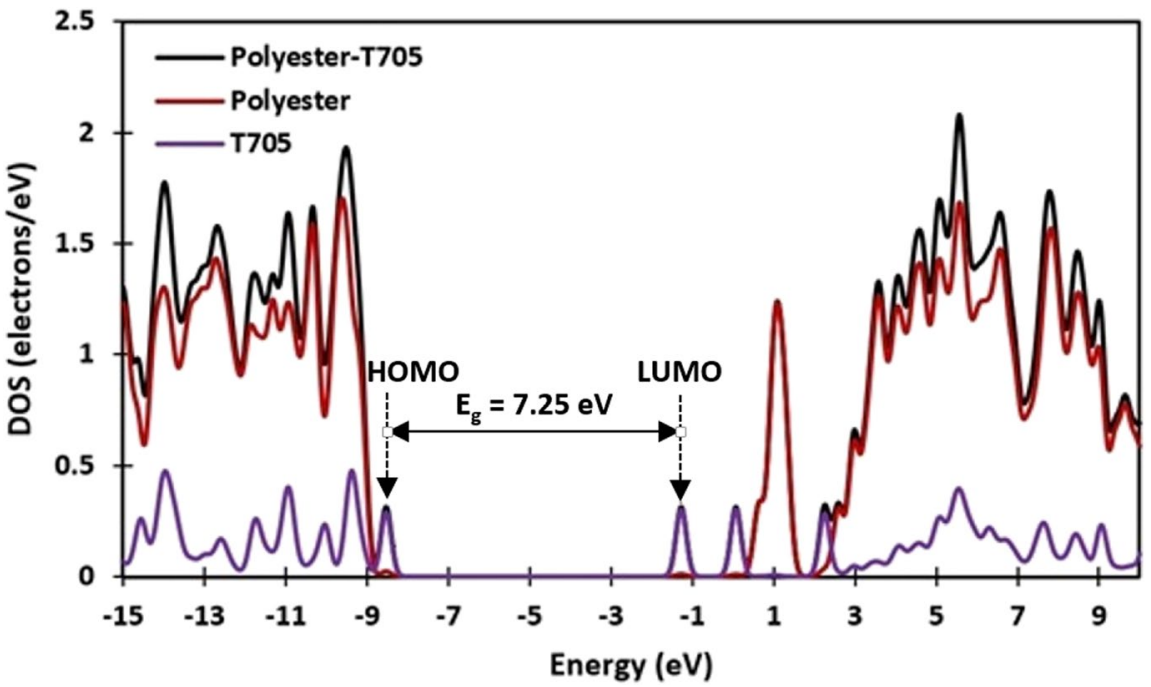


Fig. 8 (a) HOMO of polyester, b LUMO of polyester, c HOMO of polyester-T705, and d LUMO of polyesterT705. Atom colors: carbon in gray, nitrogen in blue, oxygen in red, fluorine in cyan, and hydrogen in white

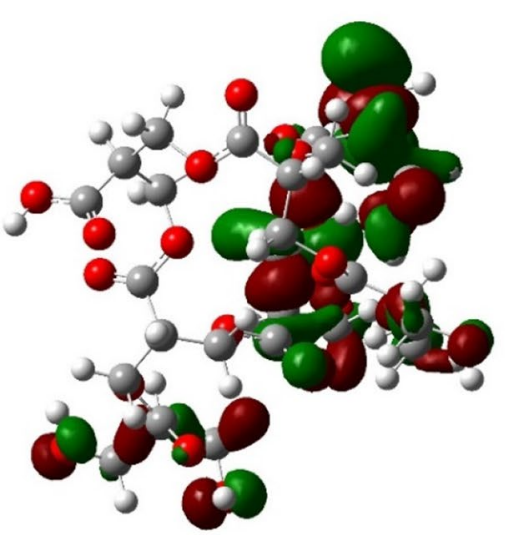

(a)

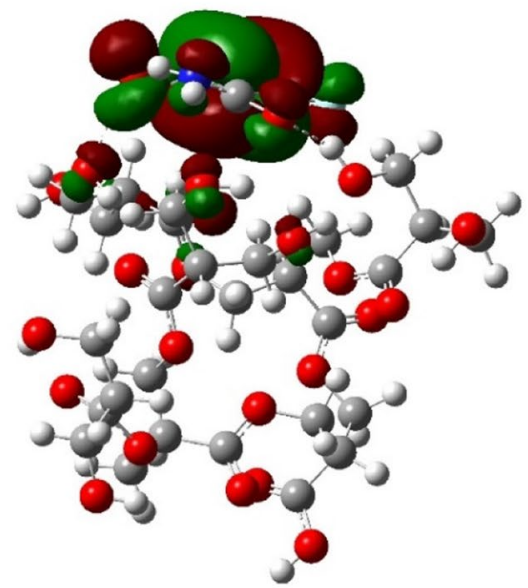

(c)

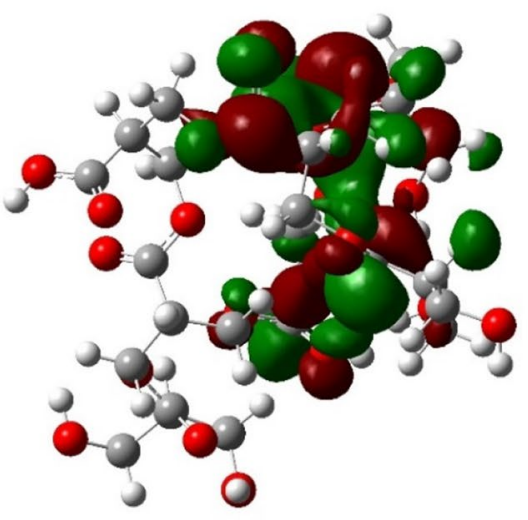

(b)

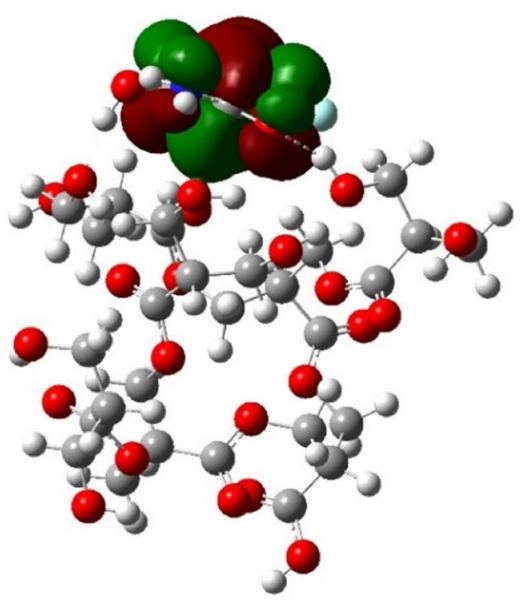

(d) the material's surface. As $\mathrm{V}_{\mathrm{el}(+\infty)}$ is estimated to be zero, we could write $\Phi=-E_{F}$. The Fermi level energy is defined as follows:

$$
E_{F}=E_{\text {Номо }}+\left(E_{\text {LUMO }}-E_{\text {Номо }}\right) / 2
$$

Based on the results in Table 1 , the $\Phi$ value of PAMAM dendrimer is changed significantly from $3.25 \mathrm{eV}$ in PAMAM to $4.78 \mathrm{eV}$ in PAMAM-T705 complex (47\%), indicating that PAMAM dendrimer is a proper $\Phi$-type sensor for T705 drug molecule. The $\Phi$ value of polyester dendrimer increases by about $0.71 \mathrm{eV}$ upon adsorption of T705 (17\%). Thus, PAMAM dendrimer is about 2.5 times stronger $\Phi$-type sensor than polyester dendrimer.
Recovery of the drug

The strength of interaction between PAMAM/polyester and T705 molecule is an important factor in determining the efficacy of nanocarriers as desorption of drug becomes difficult if a too strong host-guest interaction occurs. The recovery time for the absorbent is defined as follows:

$\tau=v_{0}^{-1} \exp \left(-E_{a d} / k T\right)$

where $\mathrm{k}$ is the Boltzmann's constant

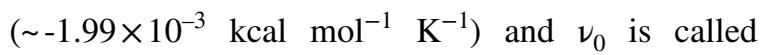
attempt frequency. According to Eq. (8), a longer 
recovery time is expected if $\mathrm{E}_{\mathrm{ad}}$ becomes more negative. Using the vacuum ultra-violet light $\left(\nu_{0} \sim 10^{16} \mathrm{~s}^{-1}\right)$ at $298 \mathrm{~K}$, the recovery time of $\mathrm{T} 705$ from the PAMAM and polyester dendrimers is calculated to be about $9.2 \times 10^{3}$ and $4.2 \times 10^{3} \mathrm{~s}$, respectively. Therefore, PAMAM and polyester do not release T705 molecule easily at physiological conditions though the recovery time assigned to T705 desorption from PAMAM $(2.56 \mathrm{~h})$ is almost two times longer than that of polyester (1.17 h.).

\section{Quantum molecular description}

To get a clear perception of the electronic structure of PAMAM- and polyester-T705 complexes, we calculated the electrophilicity index $(\omega)$. This index measures the stabilization in energy when the system acquires an additional electronic charge from the environment. In a charge transfer process, higher values of $\omega$ indicate the higher electrophilic power of the structure (N.M. O'boyle, A.L. Tenderholt, K.M. Langner 2008). Electrophilicity index is given by Eq. (11):

$\mu=-\kappa=\left(E_{\text {HOMO }}+E_{\text {LUMO }}\right) / 2$

$\eta=\left[-E_{\text {Hомо }}-\left(-E_{\text {LUMO }}\right)\right] / 2$

$\omega=\mu^{2} / 2 \eta$

where $\mu$ is the electronic chemical potential, $\kappa$ is electronegativity, and $\eta$ defines chemical hardness of the ground state (Parr and L.v. Szentpály, S. Liu, 1999). The obtained values for $\mu, \eta$, and $\omega$ are presented in Table 1. In the PAMAM-T705 complex, the electrophilicity of the complex (3.85) is to some extent higher than that of the polyester-T705 complex (3.32). Hence, in PAMAM-T705 complex, the drug adsorption on the dendrimer increases the electrophilicity and enhances the stability of the dendrimer.

\section{Conclusions}

We performed DFT calculations at the M06-2X/6$31 \mathrm{G}(\mathrm{d}, \mathrm{p})$ level of theory to investigate the potential application of PAMAM and polyester dendrimers as T705 molecule nanocarriers. Full geometry optimizations and frequency calculations showed that the binding energy and $\Delta \mathrm{H}$ of adsorption process for PAMAM (-27.26 and $-25.88 \mathrm{kcal} \mathrm{mol}^{-1}$, respectively, in solvent phase) and polyester dendrimer (-26.80 and $-17.46 \mathrm{kcal} \mathrm{mol}^{-1}$, respectively, in solvent phase) can be categorized into chemical adsorptions. The frontier molecular orbital analyses demonstrated that HOMO of PAMAM and LUMO of T705 have the main contribution in the PAMAM-T705 complex formation. The adsorption of T705 on the polyester dendrimer is affected by T705 frontier molecular orbitals, in general. The $\mathrm{E}_{\mathrm{g}}$ of PAMAM and polyester dendrimers reduced by about $32 \%$ and $27 \%$, indicating that the electrical conductance of carriers become $8.16 \times 10^{23}$ and $4.41 \times 10^{22}$ times higher, upon T705 adsorption. The $\Phi$ value of PAMAM and polyester is changed about 1.53 and $0.71 \mathrm{eV}$, respectively. Thus, PAMAM dendrimer is about 2.5 times stronger $\Phi$-type sensor than polyester dendrimer. The recovery time of T705 from the PAMAM and polyester dendrimers is calculated to be about $9.2 \times 10^{3}$ and $4.2 \times 10^{3} \mathrm{~s}$, respectively. Therefore, PAMAM and polyester do not release T705 molecule easily at physiological environment.

Author contributions Sekineh Bazyari-Delavar: Methodology, software, and investigation.

Farideh Badalkhani-Khamseh: Conceptualization, methodology, writing — original draft preparation, validation, and writing - reviewing and editing.

Azadeh Ebrahim-Habibi: Writing—reviewing and editing.

Nasser L. Hadipour: Supervision.

\section{Declarations}

Conflict of interest The authors declare no competing interests.

\section{References}

Tomalia DA (2004) Aldrichimica Acta 37:39

A.P. Dias, S. da Silva Santos, J.V. da Silva, R. Parise Filho, E.I. Ferreira, O. El Seoud, J. Giarolla, International journal of pharmaceutics (2019) 118814.

Badalkhani-Khamseh F, Ebrahim-Habibi A, Hadipour NL (2019) J Mol Recognit 32:e2757

Kesharwani P, Jain K, Jain NK (2014) Prog Polym Sci 39:268

A. Chauhan, B. Anton, M.K. Singh, Pharmaceutical applications of dendrimers, Elsevier, 2020, p. 59.

Badalkhani-Khamseh F, Ebrahim-Habibi A, Hadipour NL (2017a) J Comput Aided Mol Des 31:1097 
K. Yamamoto, T. Imaoka, M. Tanabe, T. Kambe, Chemical reviews (2019).

Esfand R, Tomalia DA (2001) Drug Discovery Today 6:427

Parrott MC, Benhabbour SR, Saab C, Lemon JA, Parker S, Valliant JF, Adronov A (2009) J Am Chem Soc 131:2906

Lim J, Simanek EE (2012) Adv Drug Deliv Rev 64:826

Feliu N, Walter MV, Montañez MI, Kunzmann A, Hult A, Nyström A, Malkoch M, Fadeel B (2012) Biomaterials 33:1970

E. Pedziwiatr-Werbicka, K. Milowska, V. Dzmitruk, M. Ionov, D. Shcharbin, M. Bryszewska, European Polymer Journal (2019).

Parashar AK, Patel P, Gupta AK, Jain NK, Kurmi BD (2019) Drug Deliv Lett 9:248

Tomalia DA, Baker H, Dewald J, Hall M, Kallos G, Martin S, Roeck J, Ryder J, Smith P (1985) Polym J 17:117

S. Akhtar, B. Chandrasekhar, M.H. Yousif, W. Renno, I.F. Benter, A.Z. El-Hashim, Nanomedicine: nanotechnology, biology and medicine 18 (2019) 78.

Holmes AM, Heylings JR, Wan K-W, Moss GP (2019) Int J Antimicrob Agents 53:500

S. Kheiriabad, M. Ghaffari, J.E.N. Dolatabadi, M.R. Hamblin, RNA interference and CRISPR technologies, Springer, 2020, p. 91.

Badalkhani-Khamseh F, Bahrami A, Ebrahim-Habibi A, Hadipour NL (2017b) Chem Phys Lett 684:103

Fischer D, Li Y, Ahlemeyer B, Krieglstein J, Kissel T (2003) Biomaterials 24:1121

S. Hong, P.R. Leroueil, E.K. Janus, J.L. Peters, M.-M. Kober, M.T. Islam, B.G. Orr, J.R. Baker Jr, M.M. Banaszak Holl, Bioconjugate chemistry 17 (2006) 728.

Winnicka K, Bielawski K, Rusak M, Bielawska A (2009) J Health Sci 55:169

Cakara D, Kleimann J, Borkovec M (2003) Macromolecules 36:4201

Mukherjee SP, Lyng FM, Garcia A, Davoren M, Byrne HJ (2010a) Toxicol Appl Pharmacol 248:259

Mukherjee SP, Davoren M, Byrne HJ (2010b) Toxicol in Vitro 24:169

Jain K, Kesharwani P, Gupta U, Jain N (2010) Int J Pharm 394:122

Svenson S (2009) Eur J Pharm Biopharm 71:445

Shi X, Lesniak W, Islam MT, MuÑiz MC, Balogh LP, Baker JR Jr (2006) Colloids Surf, A 272:139

Kolhatkar RB, Kitchens KM, Swaan PW, Ghandehari H (2007) Bioconjug Chem 18:2054

Ihre H, Hult A, Söderlind E (1996) J Am Chem Soc 118:6388

Ihre HR, Padilla De Jesús OL, Szoka FC, Fréchet JM (2002) Bioconjug Chem 13:443

P. Stenström, KTH Royal Institute of Technology, 2020.

K. Shiraki, T. Daikoku, Pharmacology \& therapeutics (2020) 107512.

Furuta Y, Takahashi K, Kuno-Maekawa M, Sangawa H, Uehara S, Kozaki K, Nomura N, Egawa H, Shiraki K (2005) Antimicrob Agents Chemother 49:981
Bai CQ, Mu JS, Kargbo D, Song YB, Niu WK, Nie WM, Kanu A, Liu WW, Wang YP, Dafae F (2016) Clin Infect Dis 63:1288

Oestereich L, Rieger T, Lüdtke A, Ruibal P, Wurr S, Pallasch E, Bockholt S, Krasemann S, Muñoz-Fontela C, Günther S (2016) J Infect Dis 213:934

H. Tani, A. Fukuma, S. Fukushi, S. Taniguchi, T. Yoshikawa, N. Iwata-Yoshikawa, Y. Sato, T. Suzuki, N. Nagata, H. Hasegawa, mSphere 1 (2016) e00061.

Dong L, Hu S, Gao J (2020) Drug Discoveries \& Therapeutics $14: 58$

G. Li, E. De Clercq, Therapeutic options for the 2019 novel coronavirus (2019-nCoV). Nature Publishing Group, 2020.

Bazyari-Delavar S, Badalkhani-Khamseh F, EbrahimHabibi A, Hadipour NL (2020) Comput Theor Chem 1189:112983

Karimzadeh S, Safaei B, Jen T-C (2021) J Mol Liq 322:114890

L. Piela, Ideas of quantum chemistry, Elsevier, 2013.

Karimzadeh S, Safaei B, Jen T-C (2020) J Mol Graph Model 101:107745

Zhao Y, Truhlar DG (2008) Theoret Chem Acc 120:215

Schmidt MW, Baldridge KK, Boatz JA, Elbert ST, Gordon MS, Jensen JH, Koseki S, Matsunaga N, Nguyen KA, Su S (1993) J Comput Chem 14:1347

Grimme S (2011) Wiley Interdisciplinary Reviews: Computational Molecular Science 1:211

Jain MMS, Barhate SD (2021) Asian Journal of Pharmaceutical Research 11:39

Reed AE, Curtiss LA, Weinhold F (1988) Chem Rev 88:899

H. Zhong, R. Quhe, Y. Wang, Z. Ni, M. Ye, Z. Song, Y. Pan, J. Yang, L. Yang, M. Lei, Scientific reports 6 (2016) 1.

C.C. Marston, G.G. Balint-Kurti, The Journal of chemical physics 91 (1989) 3571

N.M. O'boyle, A.L. Tenderholt, K.M. Langner, Journal of computational chemistry 29 (2008) 839.

Fallon L (1973) Acta Crystallographica Section B: Structural Crystallography and Crystal. Chemistry 29:2549

Hazrati MK, Bagheri Z, Bodaghi A (2017) Physica E 89:72

Hosseinian A, Vessally E, Bekhradnia A, Nejati K, Rahimpour G (2017) Thin Solid Films 640:93

R.G. Parr, L.v. Szentpály, S. Liu, Journal of the American Chemical Society 121 (1999) 1922.

Publisher's Note Springer Nature remains neutral with regard to jurisdictional claims in published maps and institutional affiliations. 